\title{
Formation of the skill of perception of pitch accent at the initial stage of learning the Japanese language
}

\author{
Anna Burakova, ${ }^{1, *}$, Tuyara Permyakova ${ }^{2}$ \\ ${ }^{1}$ Ural Federal University named after the first President of Russia B. N. Yeltsin, 620002, 19 Mira street, Ekaterinburg, Russian \\ Federation \\ ${ }^{2}$ North-Eastern Federal University named after M.K. Ammosov, 677000, 58 Belinsky str., Yakutsk (Republic of Sakha), Russian \\ Federation
}

\begin{abstract}
This paper is devoted to the formation of the skill of perception of Japanese pitch accent. Pitch accent is one of the most challenging aspects of learning Japanese. In addition, the relevance of the study is also confirmed by the fact that in Russian and Japanese textbooks for beginners there are no tasks on the perception of Japanese pitch accent. In the practical part of the study, we conducted an experiment. 23 students from Northeastern Federal University who began studying the Japanese language in September 2021 took part in this experiment. The students of the experimental group began to study the Japanese language according to the introductory phonetic course developed by A. Burakova. As a result of the study, we came to the conclusion that the tasks developed as a part of the introductory phonetic course had a positive effect on the perception of pitch accent at the initial stage of learning the Japanese language.
\end{abstract}

\section{Introduction}

In everyday communication, more than $50 \%$ of time is spent to listening and perceiving information from an interlocutor, which indicates the importance of the formation of phonetic skills [1]. There are 4 stages of the formation of these skills: perception, imitation, differentiated awareness, sound and intonation combination [2].

According to the research of T. N. Chugaeva, " $60 \%$ level of perception can be considered necessary and sufficient for the formation of the perceptual base of the target language, which allow successful perception of the spontaneous speech of native speakers and ensure full communication" [3]. According to T.S. Putilovskaya "as a rule phonetic knowledge and skills are formed at initial stages of study and then they are specified and are not significantly changed" [4]. We are share the opinion that work on phonetic skills in Japanese, including work on the perception of pitch accent, should begin with the very first lessons.

V.V. Rybin noted that pitch accent is the most difficult aspect of Japanese phonetics [5]. Pitch accent varies from word to word, and it is very difficult for almost all Japanese learners to discern and understand the correct pitch pattern [6].

There are 4 types of pitch accent in the Japanese language:

1. 頭高型 atamadaka-gata is equivalent to the first type of accentuation, when the first syllable of a word is pronounced in a high tone, and all subsequent ones are pronounced in a low tone.
2. 中高型 nakadaka-gata includes accentuation of the second and third types, when one or more syllables in the middle of a word are pronounced in a high tone, and the first and last in a low tone.

3. 尾高型 odaka-gata, the first syllable is pronounced in a low tone, and all subsequent ones in a high tone.

4. 平板型 heiban-gata corresponds to the unstressed type according to the European classification, when the first syllable in a word is pronounced in a low tone, and all subsequent ones in a high tone, including the case indicator following the word.

As E. Hirano-Cook notes, Japanese pitch accent has two functions: syntactic and distinctive functions. Due to pitch accent, the boundary of a word or phrase in a sentence is determined [7]. While V.V. Rybin distinguishes the following functions of accent in the Japanese language: the function of combining a phonetic word, a specific delimitation function, the function of recognizing a word form, the semantic function, which is present only in some cases [8]. As for the meaningful function, the following examples can be given:

\section{かきを食べました。 さけが好きです。}

Kaki wo tabemashita. Sake ga suki desu.

Due to the fact that the subjects kaki and sake are written in the hiragana syllabary, it is impossible to understand what this sentence is about. If in writing, misunderstandings can be avoided by writing nouns using hieroglyphs, then in oral speech we are forced to rely on pitch accent. With the type of pitch accent

\footnotetext{
Corresponding author: a.a.burakova@urfu.ru
} 
atamadaka-gata, the words kaki and sake will mean “oysters” (Japanese 牡蠣) and “salmon” (Japanese 鮭), with heiban-gata - "persimmon" (Japanese 柿) and “alcohol, sake" (Japanese 酒), respectively.

かきを食べました。(牡蠣)

Ka ki wo tabemashita.

I ate an oyster.

さいけが好きです。(鮭)

Sake ga suki desu.

I like salmon.

There is a point of view according to which pitch accent plays a secondary role in the understanding of the Japanese language [9]. Nevertheless, we share the opinion of Z.N. Japaridze, according to which the development of the perception skills of foreign language speech is one of the most important conditions that ensure not only the improvement of one's own pronunciation, but also the development of other skills and abilities [10]. S.I. Bernshtein insisted that exercises for the formation of hearing-and-speaking skills should develop in students their auditory observation and auditory memory.

This is necessary just because they must learn not only to pronounce correctly, but also to understand oral, audible speech. This is extremely important for mastering articulations. Auditory representations in the minds of students must enter into close association with representations of motor means, which cause corresponding auditory impressions [11].

\section{Materials and Methods}

In the majority of the existing tutorials, the information about Japanese pronunciation is limited to the postulate that "in Japanese there is no stress, all syllables should be pronounced in an even tone." The information about the types of accentuation of the Japanese language is presented in the textbooks of L. N. Nechaeva "Japanese for beginners", as well as in the textbook "We read, write and speak in Japanese" by E. V. Strugovoy and N. S. Sheftelevich. However, unfortunately the exercises aimed to develop the skill of distinguishing pitch accent are not presented. They are also absent in authentic educational-methodical complexes in the Japanese language for foreign students.

Therefore, A. A. Burakova developed an introductory phonetic course in the Japanese language, consisting of 7 lessons for 14 academic hours.

The first lesson contains basic information about the speech apparatus and phonetics of the Japanese language. In lessons 2-6, 2 rows of signs of the phonetic alphabets of hiragana and katakana are considered, lesson 7 is devoted to the topic of soft consonants. Each of lessons 2-7 presents the rules for reading long vowels and consonants, especially for reading the consonant [n] in positions before the consonants $[\mathrm{n}, \mathrm{p}, \mathrm{b}, \mathrm{m}]$ and at the end of a word. Moreover, each lesson contains tasks to distinguish the type of toning of the lexical units: the choice of a word with excellent pitch accent, the choice of the correct graphic designation of accentuation in accordance with the spoken word. After completing the exersises, the work continued based on printed materials with the words from the task with the specified accentuation and translation into Russian.

All audio materials are well-read by native speakers. In order to minimize the possible risks of a psychological fear of listening to the speech of a representative of the opposite sex of his teacher [12], the tasks were read by the representatives of both sexes. Both native speakers are professional Japanese language teachers for international students who have passed the Japanese Language Teaching Competency Test and trained at The Japan Foundation Japanese-Language Institute (Japan, Urawa).

\subsection{Participants}

The study involved 23 full-time students of NEFU named after M.K. Ammosov, who started studying the Japanese language in September 2021. During the preliminary work, the students were divided into two groups: experimental (EG) and control (CG). The experimental group included 11 students and the control group included 12. All students did not study Japanese before the university. The students of the experimental group began mastering the Japanese language according to the above-mentioned introductory phonetic course. The control group students mastered phonetic alphabets, simultaneously studying grammatical constructions and lexical units.

\subsection{Material}

The research material was the tasks presented in lesson 0 of the textbook $\left\ulcorner_{1}\right.$ 日 10 分の発音練習」. This textbook was chosen according to the following parameters: the presence of exercises on the perception of Japanese pitch accent, authentic audio recordings made by native speakers of the Tokyo dialect of the Japanese language. Moreover, none of the groups studied using this tutorial, so neither group had an advantage over the other.

\subsection{Procedure}

The students in both groups were instructed to perform pitfall understanding tasks. Before completing the exercise, the students were asked to listen to examples in which there is a fall in pitch (atamadaka-gata, nakadakagata) and in which there is no fall in pitch (odaka-gata, heiban-gata). After that, having listened to the recording once, the students completed the exercises. 


\section{Results and Discussion}

\subsection{Task 1}

The first task consisted of 30 audio files, after listening to which, it was necessary to note whether there was a fall in pitch to the verb link で す. The table below shows the number of correct answers given by students in the control and experimental groups. The greater number of correct answers in each of the tasks is highlighted in bold.

Table 1. The number of correct answers to the task 1 .

\begin{tabular}{|c|c|c|c|c|c|}
\hline № & CG & EG & № & CG & EG \\
\hline 1. & 5 & 10 & 16. & 9 & 8 \\
\hline 2. & 5 & 9 & 17. & 4 & 6 \\
\hline 3. & 4 & 9 & 18. & 7 & 6 \\
\hline 4. & 7 & 9 & 19. & 6 & 6 \\
\hline 5. & 3 & 7 & 20. & 7 & 7 \\
\hline 6. & 7 & 7 & 21. & 8 & 9 \\
\hline 7. & 10 & 7 & 22. & 7 & 8 \\
\hline 8. & 4 & 9 & 23. & 8 & 8 \\
\hline 9. & 9 & 9 & 24. & 5 & 7 \\
\hline 10. & 9 & 6 & 25. & 6 & 8 \\
\hline 11. & 9 & 7 & 26. & 4 & 7 \\
\hline 12. & 8 & 4 & 27. & 7 & 6 \\
\hline 13. & 4 & 5 & 28. & 9 & 5 \\
\hline 14. & 6 & 8 & 29. & 8 & 4 \\
\hline 15. & 2 & 5 & 30. & 5 & 7 \\
\hline
\end{tabular}

The students of the experimental group completed 30 tasks with the best results 16 . Five tasks were performed by the control and experimental groups with the same result, and only 9 tasks out of 30 were completed by the students of the control group with the best result. At the same time, in the control group, less than 6 correct answers were given for 11 tasks, while in the experimental group this indicator was 4 .

According to Figure 1, the average number of correct answers in the control group was 16 , and in the experimental group - 19.36, that is, $53 \%$ and $65 \%$, respectively.

\section{right wrong}

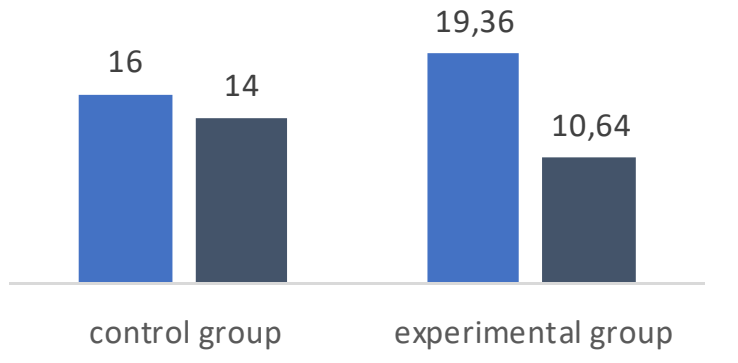

Figure. 1. The results of the task 1 .

\subsection{Task 2}

The second task also consisted of 30 audio files, after listening to which, it was necessary to determine whether there was a fall in tone on "heavy" morae.

The smallest segmentary unit of the Japanese language is mora. There are two types of morae: light and heavy. Light morae are open vowels and syllables. As a rule, students do not have any difficulties in their production. The so-called heavy or special morae are those that "contain a geminated consonant, long vowel sounds, and also nasal /N/. Despite the fact that there are only three special morae in the Japanese language, the research of K. Tamaoka and S. Makioka showed that they are quite frequent [13].

In the second task, the students of both groups with the same result coped with 8 tasks and showed the best results in 11 tasks. Less than 6 correct answers were given for 9 tasks out of 30 in each group. This may indicate that the students of the control and experimental groups have difficulty in the identification of heavy morae.

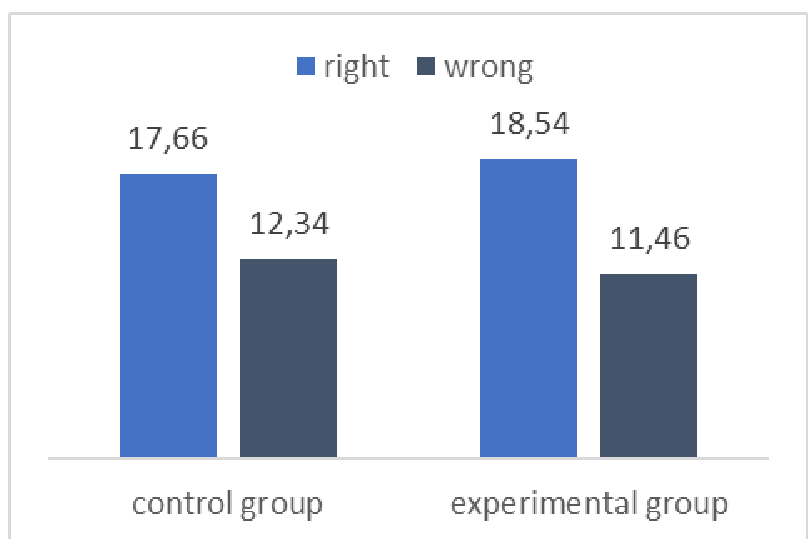

Figure 2. The results of the task 2 . 
According to Figure 2, the average number of correct answers in the control group was 17.66, and in the experimental group - 18.54, that is, $59 \%$ and $62 \%$, respectively.

Table 2. The number of correct answers to the task 2 .

\begin{tabular}{|c|c|c|c|c|c|}
\hline № & $\mathrm{CG}$ & EG & № & CG & $\mathrm{EG}$ \\
\hline 1 & 10 & 10 & 16. & 9 & 10 \\
\hline 2. & 9 & 9 & 17. & 8 & 8 \\
\hline 3. & 6 & 7 & 18. & 6 & 7 \\
\hline 4. & 5 & 6 & 19. & 2 & 3 \\
\hline 5. & 11 & 8 & 20. & 11 & 10 \\
\hline 6. & 4 & 2 & 21. & 6 & 6 \\
\hline 7. & 8 & 9 & 22 & 5 & 4 \\
\hline 8. & 9 & 10 & 23. & 8 & 5 \\
\hline 9. & 5 & 5 & 24. & 9 & 7 \\
\hline 10. & 8 & 8 & 25 & 5 & 6 \\
\hline 11. & 9 & 8 & 26. & 7 & 7 \\
\hline 12. & 11 & 9 & 27. & 7 & 8 \\
\hline 13. & 7 & 4 & 28. & 6 & 8 \\
\hline 14. & 4 & 4 & 29. & 2 & 4 \\
\hline 15. & 5 & 4 & 30. & 10 & 8 \\
\hline
\end{tabular}

\subsection{Results of two tasks}

According to Figure 2, the average number of correct answers in the control group was 17.66, and in the experimental group - 18.54, that is, $56 \%$ and $63 \%$, respectively.

Performing the second task on heavy morae, both groups showed a slightly worse result in comparison with task 1 . We associate this with the following aspects: 1) the absence of complete identity of the sound units of the Russian and Japanese languages [14], 2) in the Russian language, the length of the vowel and consonant sounds does not play a meaningful role, 3 ) in the first months of learning the Japanese language, students have not yet fully realized the difference between the syllable in Russian and the mora in the Japanese language, 4) students adjust the perception of the sounds of the Japanese language that are still unusual for them to the stable patterns of the Russian language.

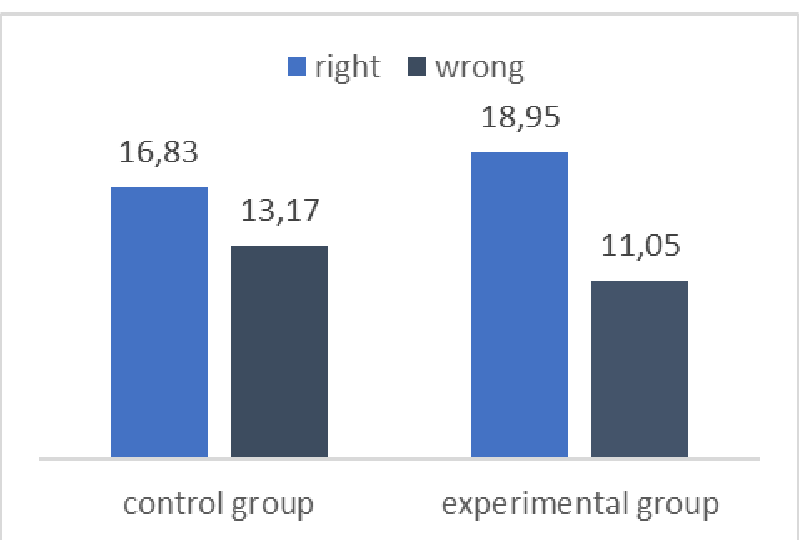

Figure 3. The results of two tasks.

\section{Conclusions}

According to the results of the study of the formation of the perception skill of Japanese pitch accent among students, we can conclude that the tasks developed for the formation of this skill within the introductory phonetic course had a positive effect on the perception of pitch accent at the initial stage of teaching the Japanese language and can be recommended for the use in the classroom by Japanese teachers.

\section{References}

1. Japan Foundation Japanese Language Teaching Series, Vol.5, "Teaching to Listen", 2nd edition. 2011)

2. He Xinxing, Russian Studies, 16 (3), 346 (2018)

3. T. N. Chugaeva, Bulletin of the Chelyabinsk State University, 8, 136 (2007)

4. T. S. Putilovskaya, University Bulletin, 8, 273 (2012)

5. V. V. Rybin, News of RSPU named after A. I. Herzen, 41, 31 (2007)

6. T. Ayusawa, T., Journal of the Phonetic Society of Japan, 2, 47 (2003).

7. E. Hirano-Cook, Japanese pitch accent acquisition by learners of Japanese: effects of training on Japanese accent instruction, perception, and production, $\mathrm{PhD}$ dissertation, 15 (University of Kansas, 2011)

8. V. V. Rybin, Phonetics of the Japanese language, 176-177 (Hyperion, Saint Petersburg, 2012)

9. K. Tamaoka, N. Saito, S. Kiyama, K. Timmer, R. G. Verdonschot, Journal of Neurolinguistics, 1, 31 (2014)

10. Z. N. Japaridze, Perceptual phonetics, 7 (Metsniyereba Tbilisi, 1985) 
11. S. I. Bernstein. Phonetic issues and teaching pronunciation, 14 (Moscow State University, Moscow, 1975)

12. V.A. Emelyanova, Theory and practice of modern humanities and natural sciences, 1 (2), 53 (2012)

13. K. Tamaoka, S. Makioka, Behavior Research Methods, Instruments, and Computers, 36 (3), 542 (2004)

14. V. V. Cherepko, Comparative typological description of the Russian and Japanese languages in order to identify sound interference in the Russian speech of the Japanese, $\mathrm{PhD}$ dissertation, 50 (RUDN University, Moscow, 2018) 